\title{
Suprascapular Nerve Block: Important Procedure in Clinical Practice
}

\author{
Marcos Rassi Fernandes ${ }^{1}$, Maria Alves Barbosa ${ }^{2}$, Ana Luiza Lima Sousa ${ }^{3}$, Gilson Cassem Ramos 4
}

\begin{abstract}
Summary: Fernandes MR, Barbosa MA, Sousa ALL, Ramos GC - Suprascapular Nerve Block: Important Procedure in Clinical Practice.
Background and objectives: Shoulder pain is a frequent complaint that results in great functional disability in the affected shoulder as well as the decrease in patients' quality of life. Suprascapular nerve block is an effective therapeutic method and has been increasingly used by anesthesiologists both for regional anesthesia and postoperative analgesia of surgeries carried out in this articulation, which justifies this review, whose main purpose was to describe the applied technique and clinical indications.
\end{abstract}

Content: It is presented the anatomy of suprascapular nerve, since its brachial plexus origin until its terminal branches, as well as general characteristics and technique employed to carry out the block of this nerve, main drugs used, volume and situations that give rise to its applications.

Conclusions: Suprascapular nerve block is a safe and extremely effective procedure in shoulder pain therapy. It also has an easy reproducibility and has been very used by professionals of many medical specialties. When it is well-indicated, this method must be taken into consideration.

Keywords: Anesthesia, Conduction; Shoulder Pain; Anatomy, Regional; Anesthetics, Local.

\section{INTRODUCTION}

Suprascapular nerve block (SSNB) is a safe and effective method to treat pain in chronic diseases that affect the shoulder, like irrecoverable injury of rotator cuff, rheumatoid arthritis, calcific tendinitis, cancer, stroke sequels and adhesive capsulitis ${ }^{1,2}$. Shoulder pain is a frequent complaint among elderly patients, which leads to a great functional disability and decrease in their quality of life. The prevalence in general population is approximately $20 \%{ }^{3}$.

This therapeutics has been increasingly used by anesthesiologists both for postoperative analgesia of surgeries carried out in this region, since pain, often severe, interferes with the rehabilitation process ${ }^{4-6}$. Other health care providers, like orthopedists, rheumatologists, neurologists and pain specialists also use this method for the desired analgesic effect in their patients ${ }^{1,7,8}$.

It is important to point out that in the last two decades there has been an increase in regional anesthesia application in

\footnotetext{
Received from the Universidade Federal de Goiás, Brazil.
}

1. MSc Student in Healthcare Sciences at Faculdade de Medicina - Univesidade Federal de Goiás (UFG); Professor at the Department of Orthopedics and Traumatology Department, Faculdade de Medicina, UFG

2. $M D, U F G$

3. PhD, Public Health; Professor at the of Graduation Program, Faculdade de Medicina UFG

4. PhD, Healthcare Sciences; Specialist in Cardiology by SBC/AMB

Submitted on: March 15, 2011.

Approved on: May 19, 2011.

Correspondence to:

Dr. Marcos Rassi Fernandes

Av. Azaléias Qd. 10 Lt. 20

Res Jardins Viena Ap de Goiânia

74935187 - Goiânia- Go, Brazil

E-mail: marcosombro@ig.com.br anesthetic practice with regard to peripheral nerve block. This technique included in this context, despite having low cost and easy reproducibility, is restricted by the lack of training of professionals in the area ${ }^{9}$.

\section{HISTORICAL ASPECTS}

The procedure can be performed in ambulatory and was initially described by Wertheim and Rovenstein, in 1941. They applied it in patients with chronic shoulder pain, although diagnosis had not been made. They stated that it was necessary to apply it as a previous resource to manipulation of affected region and advised injection of $5 \mathrm{~mL}$ of procaine $2 \%$, associated with $5 \mathrm{~mL}$ of an oily analgesic solution directly in the suprascapular incisure, site where suprascapular nerve passes under superior transverse scapular ligament. The effect duration was 4-6 weeks ${ }^{10}$. The article only described the technique to carry out SSNB. Therefore, it was not a clinical trial in which possible complications of method could be detected ${ }^{11}$.

\section{SUPRAESCAPULAR NERVE ANATOMY}

Suprascapular nerve is a mixed nerve, both motor and sensitive, originated in upper trunk of brachial plexus, $\mathrm{C} 5$ and $\mathrm{C} 6$ roots, receiving in over $50 \%$ contributions of fourth cervical root. It crosses the deep posterior triangle of neck, below omohyoid muscle and trapezium, entering the suprascapular incisure below the superior transverse scapular ligament (Figure 1). Suprascapular artery and vein run through above this ligament. The nerve provides two motor branches for supraspinatus muscle and sensitive branches to acromiocla- 


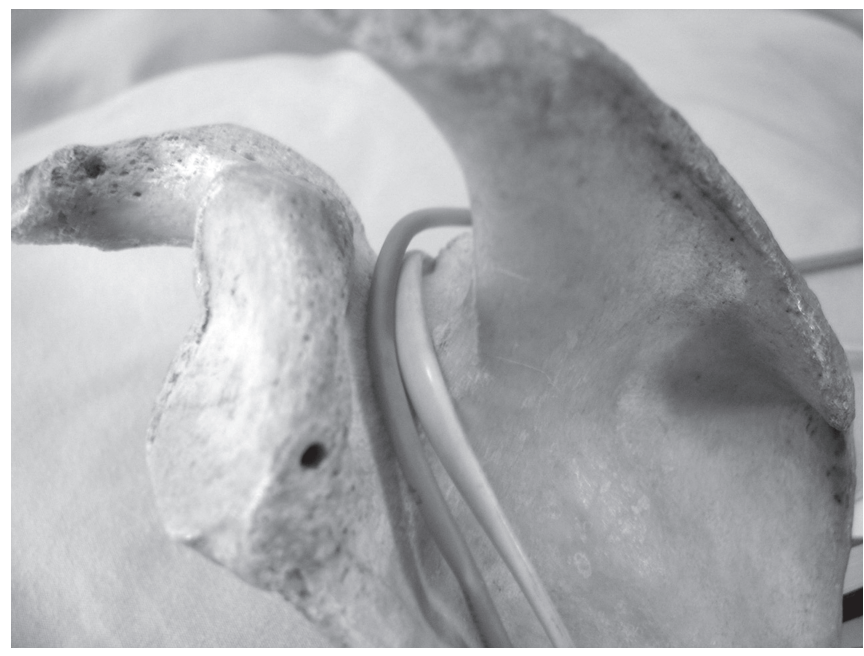

Figure 1 - Posterior View of Scapula Bone Model: Suprascapular Nerve (Light Gray) from Incisure to Spinoglenoid Fossa.

vicular and glenohumeral articulation. It continues its descending obliquous path bypassing the spinoglenoid incisure, under the inferior transverse scapular ligament present in $50 \%$ of people. It follows then towards the infraspinatus fossa, in which it provides three to four motor branches for infraspinatus muscle ${ }^{7}$ (Figure 2).

The sensitive components innervate upper and posterior part of capsule of the shoulder in addition to the acromioclavicular articulation, coracoclavicular ligament and subacromial bursa. They provide $70 \%$ of shoulder articulation sensitivity, as the rest take place through axillary nerve branches ${ }^{12}$.

These sensitive branches emerge from suprascapular nerve before and after passing below superior transverse scapular ligament ${ }^{13}$. Two to three of them pass through the scapular incisure and reach the base of coracoid process, where they perforate supraspinatus muscle, extending towards subacromial bursa ${ }^{6}$. To obtain the interruption of sensory impulses of the involved structures, it is important to know these anatomic details so that SSNB develops in a healthy way.

\section{Technique of supraescapular nerve block}

Suprascapular nerve block can be carried out both for regional anesthesia in open or arthroscopic surgeries of shoulder and postoperative analgesia in ambulatory ${ }^{3,4,6}$.

The technique consists of injecting anesthetic in supraspinatus fossa of affected shoulder, with the patient sitting down and upper limbs pending beside the body. The health care provider must palpate anatomical parameters like clavicle, acromioclavicular articulation, acromion, scapula spine and coracoid process. This entire area is sterilized with alcohol, the needle introduction site is medial to vertex obtained from two imaginary lines traced over upper edge of clavicle and anterior edge of scapula spine, laterally to the coracoid process

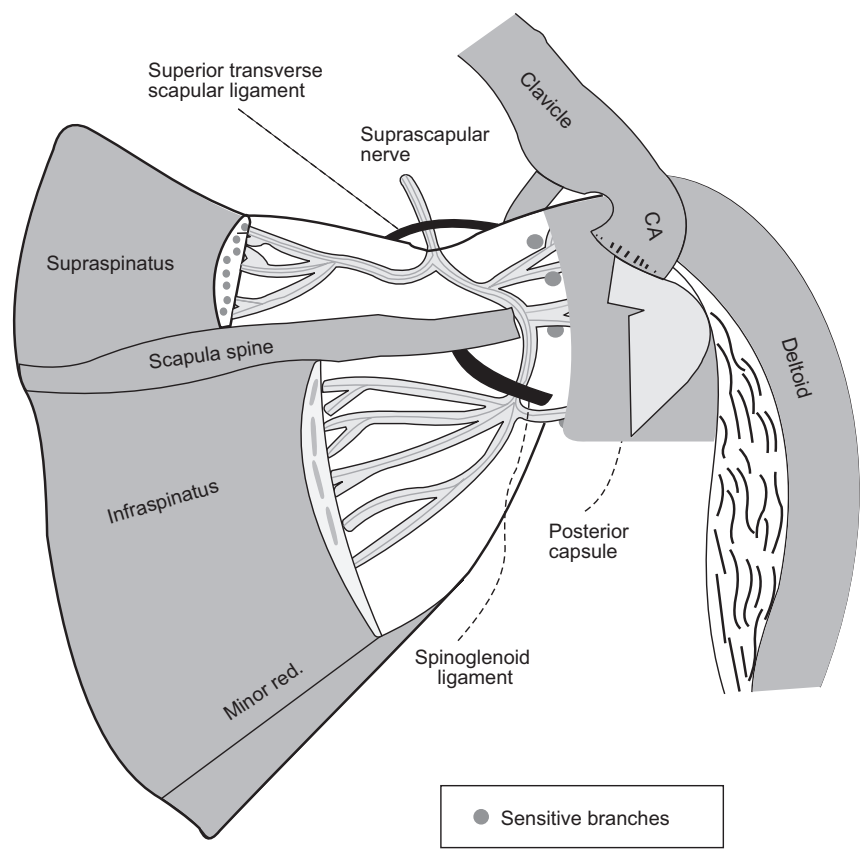

Figure 2 - Anatomy of Suprascapular Nerve and its Sensitive Branches to Upper and Posterior Part of Shoulder.

(Figures 3 and 4). It is in this location that Neviaser portal is made in the arthroscopic surgery of shoulder ${ }^{14}$. The needle is advanced in craniocaudal direction, perpendicular to skin, crossing the trapezium and supraspinatus muscles, until it reaches the supraspinatus fossa ( 3 to $4 \mathrm{~cm}$ ), adjacent to coracoid process basis where the nerve is located. Sometimes the patient reports a slight paresthesia on lateral surface of affected arm or shoulder ${ }^{15}$. The needle must be aspired, before infusion of anesthetic solution so that there is no risk this solution enters the bloodstream directly.

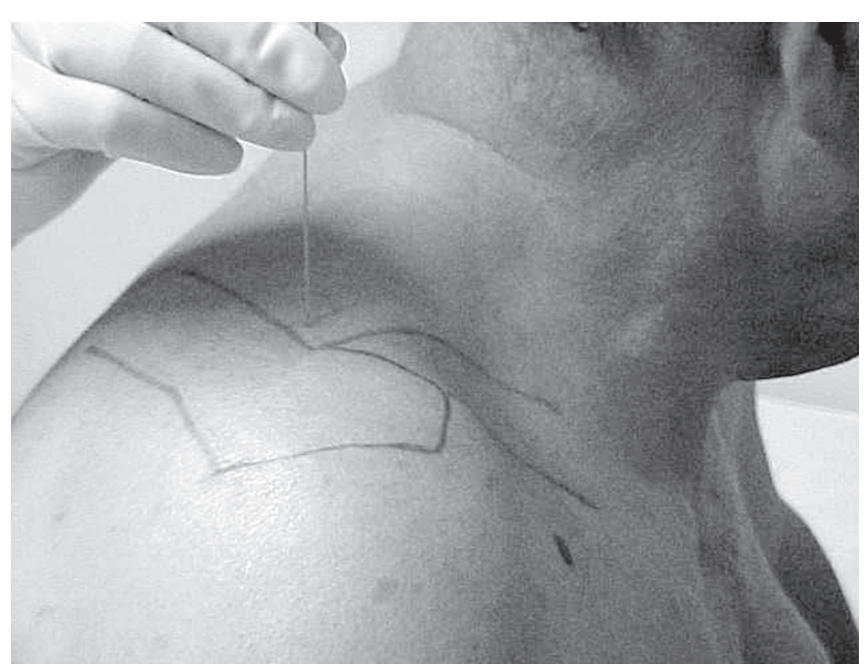

Figure 3 - Demarcation on Skin of Bone Structures of Shoulder, Demonstrating Vertex between Scapula Spine and Clavicle to Perform Suprascapular Nerve Block. 


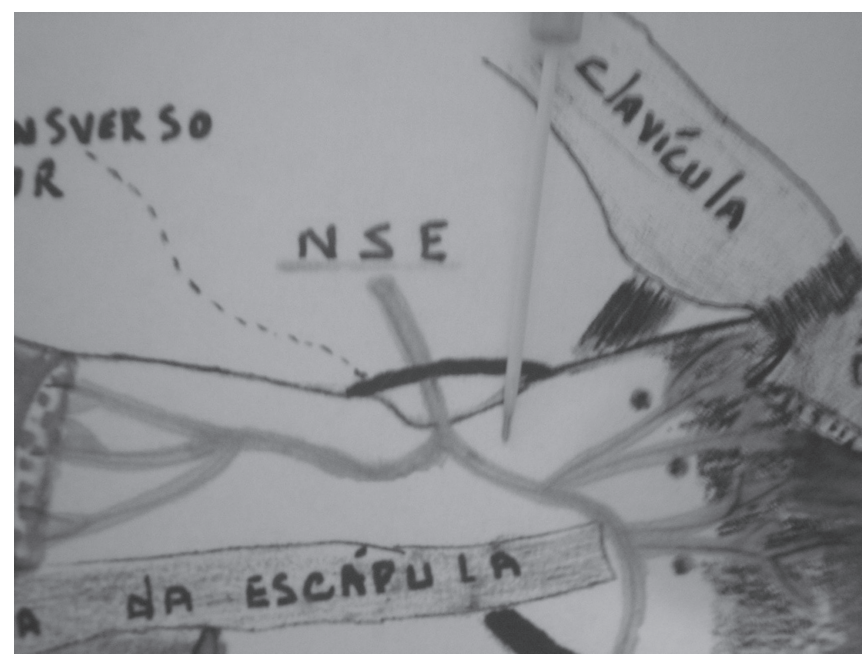

Figure 4 - Site of Introduction of Anesthetic to Block Efficacy.

This is a technique of indirect block of suprascapular nerve described by Dangoisse et al. ${ }^{16}$, in which the needle is not medially introduced until the point of entering scapular incisure, as Wertheim and Rovenstein advised (classic technique), site where there are risks of pneumothorax, brachial plexus injury and harm to suprascapular vessel and nerve. Therefore, in the indirect technique, it is not necessary to locate this incisure and to inject anesthetic solution in the floor of supraspinatus fossa, distant from direction of apex of the lung $11,15,16$.

From this description (1994) it was also possible for professionals in the field of the musculoskeletal care to use this procedure, like orthopedists and rheumatologists, as it is safer, practically eliminating the above-mentioned risks ${ }^{11,15}$.

\section{Drugs and volume to be used in SSNB}

There is no consensus in the literature about the ideal anesthetic drug to be used in SSNB. Since the its introduction ${ }^{10}$, the volume most frequently used is $10 \mathrm{~mL}$, with $0.5 \%$ bupivacaine ${ }^{11,17}$. Other authors prefer isolated $1 \%$ lidocaine ${ }^{18}$ or associated with $0.5 \%$ levobupivacaine ${ }^{12}$. Other option would also be to use $0.25 \%$ or $0.5 \%$ bupivacaine with $1: 200,000$ epinephrine ${ }^{15,19}$ or $0.75 \%$ ropivacaine 20 .

There is also a description of using local anesthetic associated with methylprednisolone as a combination to carry out SSNB ${ }^{17}$. Since it is intended to block sensitive stimulus and not have a locoregional anti-inflammatory effect, using the anesthetic alone is the most common described in the literature $4,11,12,14-16$.

With regard to volume, it is important to report that different quantities ranging from 5 to $25 \mathrm{~mL}$ have been suggested by many authors. Wassef ${ }^{21}$, Wertheim et al ${ }^{10}$ and Dangoisse et al. ${ }^{16}$ used from 3 to $8 \mathrm{~mL}$, quantities smaller than the $10 \mathrm{~mL}$ most frequently found $6,11,18,19$. Checucci et al. ${ }^{12}$, Price ${ }^{20}$ and Meier et al. ${ }^{22}$ advised $15 \mathrm{~mL}$, while Barber ${ }^{14}, 20-25 \mathrm{~mL}$.

There is a large difference of volumes injected in SSNB. Feigl et al. ${ }^{23}$ studied 34 cadavers, where two different volumes were used: $10 \mathrm{~mL}$ in right shoulders and $5 \mathrm{~mL}$ in left ones. The injected solution was Jopamidol contrast agent associated with saline solution. All cadavers were investigated under three-dimensional computed tomography and the study concluded that $5 \mathrm{~mL}$ volume would be enough to fill in lateral half of supraspinatus fossa ${ }^{23}$.

Jerosch et al. ${ }^{24}$, with the purpose of evaluating the required quantity of fluid to infiltrate supraspinatus fossa, injected different volumes of local anesthetics associated with a contrast agent $(1,2,3,4,5$ and $10 \mathrm{~mL})$ and documented it by image intensifier. The conclusion was that $10 \mathrm{~mL}$ would be more than enough to block suprascapular nerve.

Meier et al. ${ }^{22}$ described a significative increase of resistance when volumes over $10 \mathrm{~mL}$ are applied, as initial dose in continuous nerve blocks.

Therefore, there are studies suggesting the conduction of SSNB with smaller volumes of local anesthetics in regard to filling in supraspinatus fossa ${ }^{22-24}$. Nevertheless, would this volume be enough to provide an adequate duration of action to block? Randomized clinical trials comparing two or three volumes are required to answer such relevant question to the clinical practice.

\section{CLINICAL INDICATIONS}

One of most frequent shoulder pathologies with SSNB indication is adhesive capsulitis, which is a painful syndrome characterized by limitation of both active and passive movements of this articulation in all directions, and no mechanical block can explain it. Therefore, glenohumeral blocked luxation and arthrosis appear as an important differential diagnosis. The etiology is idiopathic and clinical picture is characterized by severe pain at rest and articular rigidity, as capsule of the shoulder is retractile and reduced in its normal volume. As sensitivity of the latter is given by branches from suprascapular nerve, the employment of SSNB in therapeutics of this disease is justified $11,15,18,25$.

Shoulder surgery has an acknowledged potential of being associated with important pain in the postoperative period. Many procedures for analgesia of this articulation have been used, like articular, subacromial infiltration, use of opioids, continuous interscalene block and SSNB. Since the latter is a method with low complication rate, it has been increasingly employed in the therapeutics of postoperative pain $4,6,19$. It is worth mentioning that a single block has a short duration effect, and due to the fact that suprascapular nerve is not the only one to provide sensitive branches to articular capsule of the shoulder, the pain may not be completely eliminated, but is drastically reduced $4,14,20$.

Another clinical application is employing SSNB in regional anesthesias associated with other methods to perform articular shoulder surgeries ${ }^{12,26}$. Locoregional accesses of 
intra-articular anesthetic injections and interscalene blocks of branchial plexus have also been used for this purpose, but with high incidence of adverse effects and largely dependent on the anesthesiologists' skills ${ }^{14,26}$. SSNB associated with axillary nerve block has been a safe and promising alternative to arthroscopic surgeries of shoulder, with no use of general anesthesia ${ }^{12}$.

Rheumatoid arthritis is a systemic pathology that affects articulation of the shoulder and often uses SSNB in its therapeutics, which is characterized to be a chronic inflammatory autoimmune disease, of unknown etiology that leads to deformity and destruction of articulations by bone and cartilage erosion, with different degress of deficiency. It is distributed worldwide and its prevalence varies from $0.2 \%$ to $1 \%$, affecting women twice as often as men. With progression of the disease, patients develop great disability in their routine as well as professional activities

The pain in the hemiplegic shoulder is a frequent complaint after stroke, with incidence ranging from $16 \%$ to $84 \%$, which increases hospitalization time and greatly impairs the rehabilitation process. The cause that leads to appearance of this pain is still inconclusive and controversial. The signals and symptoms are similar to what is found in a rigid, painful, non hemiplegic shoulder. Evidences in therapeutic procedures in this type of articular algia are limited. Many treatment methods have been described, from physical therapy to articular infiltration and more recently SSNB, which became another option to treat those patients ${ }^{1,27}$.

\section{Single or multiple block}

Local anesthetics are the pharmacologic agents most widely used in both regional anesthesia and pain therapy ${ }^{28}$. Temporary block prevents transmission of afferent and efferent autonomic neural stimulus between shoulder and spinal cord, which ends up normalizing certain pathologic processes that affect shoulder articulation ${ }^{11}$. The large quantity of sympathetic fibers that suprascapular nerve provides to shoulder articulation has been highlighted ${ }^{16}$.

SSNB may be performed with a single application 17-20,22 as well as multiple ones, with weekly ${ }^{11,21}$ or bimonthly ${ }^{15}$ periodic returns. There are no evidences in the literature that can determine how many blocks to use and the interval between them. Some authors use the variables improvement of pain and articular mobility as parameters for how many to apply ${ }^{11,15}$. The authors have developed a research in adhesive capsulitis patients to try to clarify this gap of knowledge.

It is important to emphasize that SSNB may be performed using nerve stimulator ${ }^{12}$, as well as be guided by ultrasom transducer ${ }^{29}$ or computed tomography ${ }^{30}$ in single injections. More recently, ultrasound-guided perineural catheter has been applied with the purpose of promoting continuous suprascapular nerve block to treat adhesive capsulitis after surgical capsular release ${ }^{31}$. 


\section{REFERÊNCIAS / REFERENCES}

1. Allen ZA, Shanahan EM, Crotty M - Does suprascapular nerve block reduce shoulder pain following stroke: a double-blind randomized controlled trial with masked outcome assessment. BMC Neurology, 2010;10:83-87.

2. Fernandes MR, Fernandes RJ - Artroscopia no tratamento da tendinite calcária refratária do ombro. Rev Bras Ortop, 2010;45:53-60.

3. Taskaynatan MA, YIlmaz B, Ozgul A et al. - Suprascapular nerve block versus steroid injection for non- specific shoulder pain. Tohoku J Exp Med, 2005;205:19-25.

4. Fredrickson MJ, Krishnan S and Chenz CY - Postoperative analgesia for shoulder surgery: a critical appraisal and review of current techniques. Anaesthesia, 2010;65:608-624.

5. Tan N, Agnew NM, Scawn ND et al. - Suprascapular nerve block for ipsilateral shoulder pain after thoracotomy with thoracic epidural analgesia: a double-blind comparison of $0.5 \%$ bupivacaine and $0.9 \%$ saline. Anesth Analg, 2002;94:199 -202.

6. Matsumoto D, Suenaga N, Oizumi N et al. - A new nerve block procedure for the suprascapular nerve based on a cadaveric study. J Shoulder Elbow Surg, 2009; 18: 607-611.

7. Fernandes MR, Fernandes RJ - Descompressão artroscópica indireta do cisto espinoglenoidal com neuropatia do supraescapular: relato de dois casos e revisão da literatura. Rev Bras Ortop, 2010;45:306-311.

8. Shanahan EM, Smith MD, Wetherall M et al. - Suprascapular nerve block in chronic shoulder pain: are the radiologists better? Ann Rheum Dis, 2004;63:1035-1040.

9. Helayel PE, Conceição DB, Conceição MJ et al. - Atitudes de anestesiologistas e médicos em especialização em anestesiologia dos CET/SBA em relação aos bloqueios nervosos dos membros superior e inferior. Rev Bras Anestesiol, 2009;59:332-340.

10. Wertheim HM, Rovenstine EA - Suprascapular nerve block. Anesthesiology, 1941;2:541-545.

11. Dahan THM, Fortin L, Pelletier M et al. - Double blind randomized clinical trial examining the efficacy of bupivacaine suprascapular nerve blocks in frozen shoulder. The Journal of Rheumatology, 2000;27:1464-1469.

12. Checcucci G, Allegra A, Bigazzi P et al. - A new technique for regional anesthesia for arthroscopic shoulder surgery based on a suprascapular nerve block and an axillary nerve block: an evaluation of the first results. Arthroscopy, 2008;24:689-696.

13. Vorster W, Lange CPE, Briet RJP et al. - The sensory branch distribution of the suprascapular nerve: An anatomic study. J Shoulder Elbow Surg, 2008; 17:500-502

14. Barber FA - Suprascapular nerve block for shoulder arthroscopy. Arthroscopy, 2005;21:1015.e1-1015.e4.

15. Checchia SL, Fregoneze M, Miyazaki AN et al. - Tratamento da capsulite adesiva com bloqueios seriados do nervo supra-escapular. Rev Bras Ortop, 2006;41:245-252 
16. Dangoisse MJ, Wilson DJ, Glynn CJ - MRI and clinical study of an easy and safe technique of suprascapular nerve blockade. Acta Anaesthesiol Belg, 1994;45:49-54

17. Shanahan EM, Ahern M, Smith M et al. - Suprascapular nerve block (using bupivacaine and methylprednisolone acetate) in chronic shoulder pain. Ann Rheum Dis, 2003;62:400-406.

18. Karatas GK, Meray J - Suprascapular nerve block for pain relief in adhesive capsulitis: comparison of 2 different techniques. Arch Phys Med Rehabil, 2002;83:593-597.

19. Singelyn FJ, Lhotel L, Fanre B - Pain relief after arthroscopic shoulder surgery: a comparison of intraarticular analgesia, suprascapular nerve block, and interscalene brachial plexus block. Anesth Analg, 2004;99:589-592.

20. Price DJ - The shoulder block: a new alternative to interscalene brachial plexus blockade for the control of postoperative shoulder pain. Anaesth Intensive Care, 2007;35:575-581.

21. Wassef MR - Suprascapular nerve block a new approach for the management of frozen shoulder. Anaesthesia, 1992;47:120-124.

22. Meier G, Bauereis C, Maurer H - The modified technique of continuous suprascapular nerve block. A safe technique in the treatment of shoulder pain. Anaesthesist, 2002;51:747-753

23. Feigl GC, Anderhuber F, Dorn C et al. - Modified lateral block of the suprascapular nerve: a safe approach and how much to inject? A morphological study. Reg Anesth Pain Med, 2007;32:488-494.
24. Jerosch J, Saad M, Greig M et al. - Suprascapular nerve block as a method of preemptive pain control in shoulder surgery. Knee Surg Sports Traumatol Arthrosc, 2008; 16:602-607.

25. Favejee MM, Huisstede BMA, Koes BW - Frozen shoulder: the effectiveness of conservative and surgical interventions-systematic review. $\mathrm{Br} \mathrm{J}$ Sports Med, 2011;45:49-56.

26. Neal JM, McDonald SB, Larkin KL et al. - Suprascapular nerve block prolongs analgesia after nonarthroscopic shoulder surgery but does not improve outcome. Anesth Analg, 2003;96:982-986.

27. Boonsong $\mathrm{P}$, Jaroenarpomwatana A, Boonhong $\mathrm{J}$ - Preliminary study of suprascapular nerve block (SSNB) in hemiplegic shoulder pain. J Med Assoc Thai, 2009;92:1669-1674.

28. Nilsson J, Madeja M, Elinder F et al. - Bupivacaine blocks N-Type inactivating $\mathrm{Kv}$ channels in the open state: no allosteric effect on inactivation kinetics. Biophys J, 2008;95:5138-5152.

29. Harmon D, Hearty C - Ultrasound-guided suprascapular nerve block technique. Pain Physician, 2007;10:743-746.

30. Schneider-Kolsky ME, Pike J, Connell DA - CT-guided suprascapular nerve blocks: a pilot study. Skeletal Radiol, 2004;33:277-282.

31. Borglum J, Bartholdy A, Hautopp H et al. - Ultrasound-guided continuous suprascapular nerve block for adhesive capsulitis: one case and a short topical review. Acta Anaesthesiol Scand, 2011;55:242-247. 